\title{
A PROSPECTIVE TRIAL OF ORAL MIFEPRISTONE AND VAGINAL MISOPROSTOL IN TERMINATION OF PREGNANCIES UPTO 63 DAYS OF GESTATION
}

\author{
Th. Digel Singh ${ }^{1}$, S. Pinky², M. Davison ${ }^{3}$ \\ ${ }^{1}$ Assistant Professor, Department of Obstetrics \& Gynaecology, JNIMS, Manipur. \\ ${ }^{2}$ Senior Resident, Department of Pathology, JNIMS, Manipur. \\ ${ }^{3}$ Consultant Gynecologist, Manipur Health Service, Manipur.
}

\begin{abstract}
OBJECTIVES: By convention, abortion is defined as pregnancy termination upto 20 weeks of gestation or less than 500 gram birth weight and can be either spontaneous or induced. Induced abortion is the medical or surgical intervention of pregnancy before the time of foetal viability. According to the Consortium on National Consensus for Medical Abortion in India, every year an average of about 11 million abortions take place annually and around 20,000 women die every year due to abortion related complications. Medical abortion is an important alternative to surgical abortion for women who do not want a surgical procedure. Various regimens have been proposed for the administration of the mifepristone/ misoprostol combination. The objectives of the study were to determine the effectiveness and side effects of the combined regime of $200 \mathrm{mg}$ oral mifepristone and $800 \mathrm{mcg}$ of vaginal misoprostol.

METHODS: This was a prospective study involving 100 women $\geq 18$ years with upto 9 weeks of gestation and attended genecology OPD for MTP. The women received $200 \mathrm{mg}$ mifepristone orally followed by $800 \mathrm{mcg}$ of vaginal misoprostol 48 hours later and were sent home after an observation period of 6 hours. They returned 14 days later for an ultrasonographic evaluation. Surgical intervention was indicated for continuing pregnancy, excessive bleeding or other serious medical conditions.

RESULTS: Of the 100 subjects, 96\% had complete abortion and 4\% had undergone surgical intervention. The mean abortion induction interval was 4.7 hours. The commonest side effect was abdominal cramps (66\%), followed by nausea (42\%) and vomiting (16\%).

CONCLUSION: It is a safe, effective, reliable, non-invasive method of medical abortion.
\end{abstract}

KEYWORDS: Mifepristone, Misoprostol, Abortion, MTP.

HOW TO CITE THIS ARTICLE: Th. Digel Singh, S. Pinky, M. Davison. "A Prospective Trial of Oral Mifepristone and Vaginal Misoprostol in Termination of Pregnancies Upto 63 Days of Gestation". Journal of Evolution of Medical and Dental Sciences 2015; Vol. 4, Issue 90, November 09; Page: 15549-15551, DOI: 10.14260/jemds/2015/2229.

INTRODUCTION: The word abortion derives from the Latin abori- to miscarry. Abortion is premature birth before a live birth is possible, and in this sense it is synonymous with miscarriage. Thus, many prefer miscarriage to refer to spontaneous foetal loss before viability. The duration of pregnancy is also used to define and classify abortions for statistical and legal purposes. World Health Organization defines abortion as pregnancy termination prior to 20 weeks of gestation or with foetus born less than 500 gram birth weight. Abortion can be classified as: Spontaneous Induced Abortion occurring without any medical or surgical intervention is referred to as spontaneous. It can be further classified as threatened, inevitable, complete, incomplete, missed and recurrent abortion. Induced abortion, on the other hand, is the medical or surgical termination of pregnancy before the time of foetal viability According to the consortium on National Consensus for Medical Abortion in India, every year an average of about 11 million abortions takes place annually and around 20,000 women die every year due to abortion related complications. Most abortion-related maternal deaths are attributable to illegal abortions.

Financial or Other, Competing Interest: None.

Submission 14-10-2015, Peer Review 15-10-2015,

Acceptance 26-10-2015, Published 07-11-2015.

Corresponding Author:

Dr. Th. Digel Singh,

Department of Obstetrics \& Gynaecology,

JNIMS, Porompat, Imphal East-795008, Manipur.

E-mail: dr_digel@rediffmail.com

DOI:10.14260/jemds/2015/2229.
Surgical termination may be in the form of cervical dilatation with uterine evacuation and curettage, or vacuum aspiration, or menstrual aspiration or in some cases a laparotomy. Medical abortion is an important alternative to surgical abortion for women who do not want a surgical procedure. The most widely researched drugs are prostaglandins and methotrexate with prostaglandins. ${ }^{1}$

Mifepristone (A synthetic steroid) is an anti-progestin that blocks the action of progesterone, a hormone necessary to maintain the pregnancy. By blocking the action of progesterone, mifepristone alters the uterine lining (Endometrium), induces menstrual bleeding and causes the uterine lining to shed.

Mifepristone also causes the cervix to soften and initiates the uterine contractions Misoprostol causes the cervix to soften and the uterus to contract, resulting in the expulsion of the uterine contents. Mifepristone in combination with the synthetic prostaglandin E1 analogue, misoprostol, administered vaginally has shown to be a highly effective method for early medical abortion. ${ }^{2}$

\section{AIMS AND OBJECTIVES:}

1. To analyse the efficacy of a combination regime of oral mifepristone and vaginal misoprostol in the termination of pregnancy between 7 and 9 weeks of gestation.

2. To assess the side effect profile of patients being treated under this regime.

MATERIALS AND METHODS: This study was carried out during a period of 1 year from 1st December 2012- 30th November 2013 and included a total of 100 cases. 
Patients were offered both medical and surgical procedure from 49 to 63 days of gestation. Patients were counselled on the risks and benefits of each procedure. And informed consent was taken for patient who agreed medical method procedure. Gestational Age was determined for all the patients by an ultrasonography (USG).

On confirmation of gestational age on USG Mifepristone $200 \mathrm{mg}$ orally was administered on day 1 and the patient was sent home. She was called back after 48 hours and $800 \mathrm{mcg}$ of Misoprostol was administered vaginally. She was kept in the hospital for a period of 4-6 hours for observation and given oral or parenteral analgesia as required. The success of the procedure was determined at the end of 2 weeks by repeat USG.

RESULTS: At the end of study periods results are analysed according to age, gravida and parity, side effects, completeness of abortion etc.

\begin{tabular}{|c|c|c|}
\hline Age (Yrs) & No. of Cases & $\mathbf{\%}$ \\
\hline$\leq 30$ yrs & 61 & 61 \\
\hline$\geq 30$ yrs & 39 & 39 \\
\hline Total 100 & $\mathbf{1 0 0}$ & $\mathbf{1 0 0}$ \\
\hline \multicolumn{2}{|c|}{ Table 1: Age wise distribution of cases in study } \\
group
\end{tabular}

In study group $61 \%$ of patients were $\leq 30$ years of age.

\begin{tabular}{|c|c|c|}
\hline Gravidity & No. of Cases & $\%$ \\
\hline Primi & 26 & 26 \\
\hline Multi & 74 & 74 \\
\hline Total & 100 & 100 \\
\hline $\begin{array}{r}\text { Table 2: Gr } \\
\text { of ca }\end{array}$ & $\begin{array}{l}\text { e distribution } \\
\text { y group }\end{array}$ & \\
\hline
\end{tabular}

In the present study $26 \%$ of the patients were primigravida and $74 \%$ were multigravida.

\begin{tabular}{|c|c|c|}
\hline Side Effects & No. of Cases & $\mathbf{\%}$ \\
\hline Abdominal cramps & 66 & 66 \\
\hline Nausea & 42 & 42 \\
\hline Vomiting & 16 & 16 \\
\hline Diarrhoea & 6 & 6 \\
\hline Fever & 9 & 9 \\
\hline Chills & 62 & 62 \\
\hline Table 3: Side effect wise distribution in study group \\
\hline
\end{tabular}

The most common side effect was abdominal cramps (66\%) followed by chills (62\%) and nausea (42\%). The abdominal cramps and chills were observed on the day of administration of misoprostol i.e. 48hours after administration of oral mifepristone.

\begin{tabular}{|c|c|c|c|}
\hline \multirow{2}{*}{ Parameter } & Primigravida & Multigravida & $\begin{array}{c}\text { P } \\
\text { value }\end{array}$ \\
\hline $\begin{array}{c}\text { Onset of } \\
\text { bleeding }\end{array}$ & $4.79 \pm 0.71$ & $4.73 \pm 0.74$ & 0.72 \\
\hline \multicolumn{3}{|c|}{$\begin{array}{c}\text { Table 4: Comparison of onset of bleeding } \\
\text { after administration of misoprostol, } \\
\text { according to gravida (in Hrs.) }\end{array}$} \\
\hline \multicolumn{4}{|c|}{}
\end{tabular}

There were no significant differences between primigravida and multigravida in the onset of bleeding.

\begin{tabular}{|c|c|c|}
\hline Outcome & No. of Cases & \% \\
\hline Complete & 96 & 96 \\
\hline Incomplete & 4 & 4 \\
\hline Total & $\mathbf{1 0 0}$ & $\mathbf{1 0 0}$ \\
\hline \multicolumn{2}{|c|}{ Table 5: Outcome wise distribution } \\
of cases in study group \\
\hline
\end{tabular}

Of the 100 cases studied, $96 \%$ showed complete abortions, incomplete abortions rate was $4 \%$.

\begin{tabular}{|c|c|c|}
\hline \multirow{2}{*}{ Gestational age } & \multicolumn{2}{|c|}{ Outcome } \\
\cline { 2 - 3 } & Complete & Incomplete \\
\hline 7- 8weeeks & 52 & 3 \\
\hline 8.1- 9weeks & 44 & 1 \\
\hline Total & $\mathbf{9 6}$ & $\mathbf{4}$ \\
\hline \multicolumn{2}{|c|}{ Table 6: Comparison of gestational age \& outcome } \\
\hline
\end{tabular}

There was no statistically significant association between the gestational age of the patient and the outcome.

DISCUSSION: $\leq$ before 30 years of age the MTP practices have undergone a sea change over the years. Medical abortion has a great potential of being the modern, reliable, safe and noninvasive method of termination of pregnancy which can serve large number of women particularly in developing countries like India. The safety of the procedure is therefore of global public health importance. In the current study $61 \%$ of the patients were 30 years of age. Mean age was 24.4 years. In a study conducted by Sonal $\mathrm{K}$, of the 50 patients who underwent medical abortion the mean age was 26.44 and were less than 30years of age. ${ }^{3}$

In a study by Schaff E.A. et al, of a total 778 patients who were administered $800 \mathrm{mcg}$ vaginal misoprostol 48 hours after $200 \mathrm{mg}$ oral mifepristone, the mean age was 28 years. ${ }^{4}$ In the present study $26 \%$ of the patients were primigravida and $74 \%$ were multigravida . In a study by Ashok P.W. et al, out of a total of 1942 patients for whom parity was documented 923(47.5\%) were primigravida and $1019(52.5 \%)$ had one or more previous pregnancies. ${ }^{5}$ In a study by Bennett I. M et al of 1,309 patients who underwent medical abortion, $24.9 \%$ were primigravida The incidence of primigravida is probably on the rise on account of the current socio- economic scenario where the woman of today is more career oriented.

Medical abortion provides a safe and effective alternative without subjecting the woman to the trauma and complication of a surgical intervention.In the present study, the most common side effect was abdominal cramps (66\%) followed by chills (62\%) and nausea (42\%). In a study conducted by Sonal K, the most common side effects were abdominal cramps (74\%), nausea $(42 \%)$ and vomiting $(22 \%) .^{3}$ The study by Schaff E.A et.al, of 730 patients showed adverse effects that were reportedly made worse from either mifepristone or misoprostol compared with the baseline of symptoms from early pregnancy.

Cramping (Nearly universal) and nausea (Nearly two thirds of patients) were the most commonly reported adverse effects, and headaches (Nearly one quarter) were the findings of the preceded adverse effects. ${ }^{6}$ In another study by Schaff E.A. et al of 933 patients, the most common mifepristone- related side effects were nausea and cramping; misoprostol related side effects included cramping, fever and chills. ${ }^{7}$ Onset of bleeding was not significant in primigravida patients as compared to multigravida patients in the present study. The mean time interval from administration of misoprostol to the the onset of bleeding was 4.69 hours in primigravida and 4.76 hours in multigravida.

In a study by Schaff $A$ et al, the time of onset of bleeding after administration of misoprostol was $<4$ hours in $86 \%$ of the patients, 4 to 24 hours in $12 \%$ of the patients and $>24$ hours in the remaining $2 \%$ of the patients. ${ }^{5}$

In a study by Ashok P.W et al, the mean induction abortion interval was 4.15 hours with a range among those observed from 0.30 to 13.25 hours. ${ }^{5}$ In an another study of 933 subjects by Schaff E. A et al, of the 746 subjects who had no or minimal bleeding before misoprostol, $80 \%$ bleed within 4 hour and $98 \%$ within 24 hour of using misoprostol. 56 In the current study, the mean induction - abortion interval was 4.7 hours. 
There was no statistically significant difference in the onset of bleeding among primigravidas $(4.79 \pm 0.71$ hours $)$ and multigravida (4.71 \pm 0.74 hours) ( $p>0.05)$ In our study there were no cases who started bleeding with mifepristone alone. Bleeding started only after administration of misoprostol. Although there were 4 cases of incomplete abortion, all the patients responded to Misoprostol with bleeding per vaginum, on the same day of administration.

Surgical interventions were required in 4 cases, however blood transfusion was not observed in any of the subjects. As vaginal administration of misoprostol results in sustained blood level of drug, rather than a quick peak level and rapid metabolism noted after oral administration, a profile that might explain the greater effectiveness in patients with advanced gestational age. ${ }^{4}$ In the current study, out of the 100 patients enrolled in the study, 96 were complete abortion, 4 were incomplete abortions and none of the patients lost to follow up.

Thus, the need for a safe and effective method of medical abortion was expressed by WHO in 1978 and the mifepristone/misoprostol combination goes a long way towards fulfilling this concept. In a study by Schaff E.A et al, of the 933 subjects, 906 (97\%) had complete medical abortions, 22 had surgical intervention, two were protocol failures, and three were lost to follow up. ${ }^{7}$

In a study conducted by Sonal K, out of 50 patients, 44 were complete abortions (95.6\%), 2(4.35\%) were incomplete abortions and 4 were lost to follow up. ${ }^{3}$ In a study by Bennett I.M et al, of 1309 patients $96.5 \%$ had a complete abortion. ${ }^{8}$ In a study by Ashok P.W et al, out of 1961 subjects, 1912 had a complete abortion with no need of surgical intervention. Thus the success rate was $97.5 \% .{ }^{5}$

CONCLUSION: Medical abortion with 200mg oral mifepristone and $800 \mathrm{mcg}$ vaginal misoprostol is an effective, safe, reliable and non-invasive method. The drug is licensed for its use upto 9 weeks of gestation; this prompts earlier referral and reduces the morbidity associated with increasing gestation. The mandatory follow up visit provides an excellent opportunity for re- enforcing contraceptive counselling. In our study, out of 100 patients, 61 patients were $\leq 30$ years and 39 patients were $\geq 30$ years. Out of 100 patients 26 were primigravida and 74 were multigravida and there were 55 cases between 7-8 weeks of gestation and 45 were between 8.1-9 weeks of gestation.

The most common side effect was abdominal cramps (66\%), followed by chills (62\%) and nausea (42\%). The outcome of the study was $96 \%$ complete and $4 \%$ incomplete abortion.
The patient who had incomplete abortion were treated by surgical aspiration. Medical abortion by its nature has liberated $96 \%$ of women from rare but serious complications of infections, perforation and anaesthetic mishaps and thereby has a positive implication on reproductive health of women seeking abortion services.

The mean duration when the bleeding started after administration of misoprostol in primigravida was 4.79 hours and in multi gravida was 4-73 hours. There was no requirement of blood transfusion or hospital admission. The availability of this low cost medical treatment using agents which do not require special cold storage and transport facilities and negligible operating theatre time makes this provision of safe abortion feasible in developing country settings, like India, where medical facilities are limited.

\section{REFERENCES:}

1. Spitz I, Barden C, Benton L amd Robbins A. Early pregnancy termination with mifepristone and misoprostol in the United States. N Eng J Med 1998; 338: 1241-47.

2. Ashok PW, Templeton A, Wagarachchi PT, Flett GM. Factors affecting the outcome of early medical abortion: a review of 4132 consecutive cases. BJOG 2002:109: 1281-9.

3. Sonal K, Meenal P, Hemant D. A prospective trial using mifepristone and Vaginal Misoprostol in termination of pregnancies upto 63 days of gestation. J of Obstetrics and Gynaecology of India. 2013; 63(6): 370-372.

4. Schaff EA et al. Vaginal Misoprostol Administered 1, 2, or 3 Days After Mifepristone for Early Medical Abortion. JAMA 2000; 284(15): 1948-53. doi: 10.1001/jama.284.15.1948

5. Ashok PW et al. An effective regimen for early medical abortion: a report of 2000 consecutive cases. Human Reproduction 1998; 13(10): 2962-65

6. Schaff EA et al. Low dose mifepristone followed by vaginal misoprostol at 48 hours for abortion upto 63 days. Contraception 2000; 61(1): 41-6.

7. Schaff EA, Eisinger SH, Stadalius LS, Franks P, Gore BZ and Poppema S. Low- dose mifepristone $200 \mathrm{mg}$ and vaginal misoprostol for abortion. Contraception 1999; 59: 1-6.

8. Benett LM et al. Early abortion in family medicine: Clinical outcomes. Ann Fam Med 2009; 7: 527-33.

Doi: 10.1370/afm. 1051. 